\title{
Taraz Al Akhbar in Persian Literature and Culture
}

\author{
Mohammad Baqere Kamaladdini*, Morteza Ghiasi** \\ Payame Noor University, Yazd, Islamic Republic of Iran \\ ${ }^{*, * * E-m a i l ~ a d d r e s s: ~ k a m a l a d d i n i @ y a h o o . c o m ~, ~ t a n h a 6064 @ y a h o o . c o m ~}$
}

\begin{abstract}
Taraz Al Akhbar, the effect of Abdel Nabi poetry and storytelling (1589-1980); is a collection of poem and prose texts that is valuable from the perspective of storytelling. This anthology has literary value for the sake of diversity of poem and prose texts, and it is an important source for many literary studies. In this article after the introducing the writer, the main framework of the book based on four categories of war, banquet, love, and agility, as well as the literary value was investigated. The prologue was noticed for consideration of invention of stories, story attribute, story teller, predominance of story teller, income and issues of story teller, and customs of appropriate reading. The overview of imagery in this effect, particularly; imageries, metaphors, exaggeration, and incorporation of noticeable description such as musical instruments, elephant, and Hippo, which were less seen in the Persian literature; was included in this article. The salience of epic was shown in the chapter of war.
\end{abstract}

Keywords: Taraz Al Akhbar; Abdelnabi Fakhrozamani; poem and prose; storytelling; imagery

\section{INTRODUCTION}

Since the Persian literature and culture is very wide, there are collections in Persian literary works that still remain largely unknown and underutilized for the visibility and use of the Persian language and culture enthusiasts. Among these works, Taraz Al Akhbar by Abdel Nabi Fakhr Alzamani (late 10th-early 11th century) is a priceless and precious collection. It is a collection of different poets including known and unknown ones which has added to its literary value. In this useful collection, the author has used the selected poems and prose texts of his era's poets and writers- that indicates the content value of the book- in order to express the elements used in storytelling to learn about storytellers.

Recognition means such as pre-reading of stories and elements used in different stories such as shields, horses, and so on in epic tales or wine, lyricism and etc. in the scene of lyrical love stories or elements in agility stories with beautiful poetry and prose descriptions are the existing examples that are very useful in storytelling. Taraz Al Akhbar is one of the most detailed collections of Persian poetry and prose that is also very beneficial for scholars of history, literature and culture. This collection makes a substantial contribution to storytellers and is introduced as a wealth of prose and poetry from various writers who are familiar with poetry. Author of the book is a storyteller, scholar and skillful poet who know the secret of storytelling in his strong memory. 
This brief aims to introduce different aspects of this complex to researchers and storytellers, musicians and enthusiasts in stories and descriptions in prose, poetry and literature. It is hoped that in this way, it would be actually beneficial. Taraz Al Akhbar exists in the manuscript edition and its first half has been corrected by the writer of these lines.

\section{RESEARCH BACKGROUND}

In the field of manuscript edition of Taraz Al Akhbar wick is one of the useful and valuable treasures of Persian literature, particularly in terms of storytelling and prose, an article entitled "A look at Taraz Al Akhbar" by doctor Shafie Kadkani is available on the critical introduction to some of the current items in poetry and prose. In an article in Iran Letter magazine, ninth year, Number 2, 1950 by Doctor Mohammed Jafar Mahjoub, the aspect of storytelling in Taraz Al Akhbar has been discussed. In this paper, this burdensome work is studied in terms of literary value, the importance of storytelling and variety of poems on prose. About The book writer's biography, there are many works in Tazkere Meykhane.

\section{1. Life and works of Abdel Nabi Fakhr Alzamani}

Everything that is available about the biography of Abdel Nabi Fakhr Alzamani is included in Tazkere Meykhane by Ahmad Golchin. Mullah Abdul Nabi was born in Qazvin, his father Khalaf Beyg had a business in Qazvin and was a Sufi person. Fakhr Alzaman was the maternal ancestor of Abdel Nabi and one of the descendants of Khwaja 'Abd Allah Ansari who was the judicial officer of Qazvin. Abdel Nabi grew up in Qazvin and an enthusiasm for poetry from the early beginning of his life and had the pseudonym of "Ezzati". Abdel Nabi had a taste of the storytelling and his memory was so high to remember teh story of Amir Hamza and then memorized it. (Anthology of meanings, Ahmad, (1920) Tazkere Meykhane, Tehran, Iqbal / pp. 10 and 11).

It seems that the important part of his life begins with attendance of Mirza Aman Ullah because as was mentioned, his poetic taste worked with the attendance of Mirza Aman Ullah who had a poetry book.

His most important writings are:

1. Taraz Al Akhbar, 2. Datoor Alsohafa, 3. Navader Alhekayat or Bahrol Navader, 4. Tazkere Meykhane

\section{2. Storytelling and poetry by Abdel Nabi}

Fakhr Alzamani traveled to Mashhad when he was 19 years old and then became eager to travel to India after hearing the descriptions of that country from Indians. He was caught up in India when he was young and achieved perfect skills in storytelling by doing some practices. He knew his expertise in storytelling because of his strong memory (Ibid.).

\section{3. The main structure of Taraz Al Akhbar}

Abdel Nabi Fakhr Alzamani has written Taraz Al Akhbar for story tellers that is a collection of poems and prose of various poets of the Roudaki era to the early of 11 th century (during the life of the author). But the important point in the importance of this book in addition to its usefulness for storytelling is that this book is a treasure full of beautiful poetry 
and prose texts with various topics which has added to its literary value and also is a Tremendous resource for research purposes in the wide circle of literary history, culture and Persian literature.

This book includes a beautiful preface in praise of the Prophet with an artistic prose which is beautifully written. After that, the introduction consists of five chapters that will be discussed further. After the preface and introduction, the author has included the poems from different poets as pre-reading on different topics in order to become familiar the story tellers with the traditions of pre-reading of every issue or story, before continuing to it. The author has brought the first example of readings entitled "Preaching and its examples for the prereading of storyteller in the combatant of Ferdowsi's Shahnameh" and brings pre-reading examples from different poets.

He has brought a variety of other poems by various poets on the occasion of their prereading with various topics such as pre-reading for love stories, pre-reading of agility, Eid and presence in chiefs and kings a. Finally, the text book includes stories of four "combat", "festivity", "love" and "agility". For each of these issues, he has brought twelve tops in which relevant subsets are also addressed.

\section{4. Some features of the manuscript of Taraz Al Akhbar}

Hieroglyphics was on the beauty from the Timurid era, Mir Ali Tabrizi, Sultan Mohammad Mashhadi, Mir Ali Heravi applied changes or corrections in Hieroglyphics but it was like before Such that: P was written as b, ch as j, d as "Dal", Zh as z, when as "Key", What as "Chi" and no as "Ni". This Hieroglyphics was seen until Shahrokh era. (Bahar, Mohammad Taghi (1953) Stylistics Volume 3, Tehran, Sepehr / p 306).

The full version of Taraz Al Akhbar is version 358 available in the Library of Parliament which is scripted by Sayyid Mohammed bin Masoud bin Ahmed al-Husseini Bahari on 27 Safar 1641 AH. In This version of Taraz Al Akhbar also mentioned features are evident. Writing style and spelling of some words used in this edition is quite different from today; or example, instead of using "Zal" instead of "Ze" in the word of Marghzar in writing specifically about the preposition and the complement cascade, such as in the words of "get" or "conquest"; For example, the word 'Llfam. "Use the letters A, B, C instead of n, c and is also highlighted in the way of writing. Replacing some of the letters, combines words to make a point of beauty in the composition. Each class is divided into twelve categories as;

For stories with the subject of martial there are twelve tops as:

Hazrat Seyed Almerselyn votes a defining figure of the blessed pen, inkwell and paper, the adjective forms of struggle, heroism and vengeance of Al Farsan and saber and overcomes the enemy and the like, all kinds of weapons from swords and bow and arrow and spear and mace and ax, throngs, forts and gun down the definition, types and dialogue of army commanders, the dogma and arms combat wear and their determination to march unit commander, the characters overcome some kinds of wars sunrise and sunset that are faithful and the character trait of conquering and plundering in hand and that will be a Muslim. This century is the century of this season, the "battle", the saga of the Timurid and Safavid era are often related.

The sky arches and a circular hole was like a palace networks and

When you release the arrow from the bow

Light shines so that when the cup was poured 
It was like red agate and the pearl white

And lighting so that when it is placed in the hands

No palm wine goblets wine goblets thou knowest not

Lord Give Abdel Nabi language

Apart from the praise and admiration that I read a story

Now, one accompanied with heart and tongue

Then they praise his praise

And in that story, lyrical theme, the twelve tops are:

Trait wine taverns and bends, and Jaam Saqi character and glass and jovial character, entertainers and singing and making melody trait, the trait spring thunder and rain scholar and cheery flower seed clouds and wind, the property is owned by whatever means, in whatever attribute command that belongs attribute sunrise and sunset - the trait orchard fruit, mango and attributes mansions and inns, mountains, and plains, hunting and animal forms the hunting of wild animals and birds and Sba attribute wicket by hitting interview, all kinds of celebrations filled Juan M. and candles and lights (Ibid.).

This section describes the attributes of wine and pub bend thunder and rain, clouds, wind and cheery New Year, rising sun, orchard fruit and a mango seed varieties and the role is full of celebrations and journalist. Example, the following verses describe Sanei Larry "to" states:

The stories are the subject of romance, a dozen prominent are:

Hassan heart and love in terms of character, the property owner Hasan Al Janan, a trait nannies and servants and slave girls, horses, seeking dialogue and desirable trait in love with each other, call each other lovers of cute and needs and disability beloved rebellious lovers, the character of sunrise and sunset, the characteristic amplitude of wine, crying and restlessness love and love to addressing the ultimate way to address anxiety and other things to consider dropping the tears and fortune, and the candle for writing love letters to her lover and beloved, Joiner night, the bride and attribute the morning Joiner - the spousal characteristics and the birth of the child (Ibid.).

In this part, the subject of love was the most beautiful part of the description and Hassan hearts love and respect, love and desire to seek dialogue with each other and cry love is meeting night. In the last section, the stories that are the subject of agility, the twelve tops are:

The adjective gold jewelry and the like, messengers, harness and tether massive dagger and sling, fair women, witches, giants, and the gorilla and the like, deserts and difficult ways, skinny horses, companion's master mode and industry the trait sun rises, the character and life of the court and executioner (Ibid.).

However, eventually the book belongs to the class of books that describe both the intellect and the soul, wisdom, words, honesty, special and general advice, efforts and generosity and justice, keeping secrets, obedience and asceticism and devotion, relief, sorrow, peace in the world, Jane, and their answer letters, correspondence, masters and healers and doctors and businessmen and Muhtasibs and calligraphy and painting, etc., send correspondence Taliban and favorable father and son ... in spite of Sadat and preachers and worship and the trait of Ramadan and Eid al-Fitr and Eid al-Adha children and youth and old 
age, in spite of the sea and the ship sinking and, in spite of the Phoenix and Dragon, ... a variety of loading and speak and chants ...

\section{5. Literary value of Taraz Al Akhbar}

Poem: The lyrics have very different meanings for the induction of various descriptions, elegant and impressive expression of the literary value of this collection. Uing the Persian language poets such as name and address, and the names of famous poets met, and the on the other hand, the importance of storytelling and storytelling lyrics, the most striking feature of this work is in the field of Persian literature, i.e. Al Akhbar has the class war of the great poets of the early and late beautiful lyrics like:

Rudaki, Elemental Azrqy Kamyary, Sanei, mystery, consistency, Adib Sabir, Sirajuddin Safi Ray, J. Zd, Khaghani, Anwar, Abdul Razzaq al- Jamal, Kamal al-Din Ismail, MM Heravi, Imam Fakhr Razi Amir Akhsygty, Imad Shahriari, Othman Mokhtari, neishaboori Safi, Rashid Vtvat, Masud Saad Salman, Mojiri Bylghany, Tbyan Tbny, Sharaf al- Muqbil, Zaheer Faryab, Abdul Alvas Jabali, Abu Faraj Rooney, Rafi Uddin Abhari, Sharaf al-Din alKirmani Afzal, Salman Savedji, Lame, Farid squint-eyed, Maulana Estarabadi system, Mirza Sharaf Jahan Qazwini, optical judge, Abu Almaly neyshaboori, Dkny Tahir Shah, Hussain Sanaei, crescent, Chlpy, hey, Vfy, Taleb Amoli, Mirza Ghazi, Aqdasi, Mir Sanjar bin Haider, Myrzafsyhy, Shqayy wise, learned Shirzai, Mirza lost the unseen, Wise Rkna, Ghiasi squash, sage mystic, Talib Kalim, Muhammad Quli Salim Mirza knowledge, Myrdvsty Samarkand, Shrary Hamadani, Zaki Hamadani, boom Hamadani, blame Taklv, Foroozi Kashani, Nadim Gilani Asayb, Estarabadi, Amir Maleki Qazwini, Ghyasay fair and judicial Haider ... " it adds to the diversity of literary value.

Prose list also included in this collection, it has a nice battles which are:

"Shahnameh, Joseph, Z., Garshasbnameh Asadi Tusi, Hdyqh Wise Sanaei, logic ot Tayr, Masnavi Rome, Vis and Ramin pride, Gorgan, Khamse military Sheikh, Khamse Yamyr Khosro Dehlavi, Koran Alsdyn, Bostan by Sheikh Sadi, Golestan he, O. Shaikh Jam, seven Orang Maulana Jami, Hatefi Tymvrnamh, Shhnshah letter Jnabdy Mirza Qasim, Ibn Husam enable a Lily and Willow school of Shiraz, Shah Jalal beg, Vchvgan his balls, Farhad and Shirin wild, in order Nazrv he Khldbryn his bread and halva Sheikh Baha Mohammed, Rumi Tzrvy Qazwini, Wise Rkna fantasy series, Tldmn Sheikh grace, purity determination Masnavi, Rumi emerged Andrznamh Hakim Arif, Khosrow and Shirin Mirza Jafar, Masnavi customary, the eunuchs, stumbling a Sanaei Hussein, the Taliban Jhangyrnamh Amelie, noted Alysh Yousefi, seven bodies Tklv blame, Khosrow and Shirin, he Bharaz garden book" (ibid.).

So regardless of Akhbar-class technical values, from the beauty of this collection of literature and poets extent necessary for them to be familiar with the names and works of poetry or alleged of a valuable inelegant and it's about respect.

Prose: Prose on top Akhbar, in tandem with the order, describing various topics to show off, but heavy and simple because there is some long and wordy and vocabulary used to describe the long and difficult causes fatigue in the audience and the sooner you understand or not understand, especially for an audience is the public.

The decline of Prose, Arabic compounds and crude expressions, phrases replacement greyhound lifeless instead of sweet Persian proverbs, usage of verbs with different prefixes and different concubine and traditional unlikely gathering and continuity conditions that 
which way was used for the particle and suffixes, adjective and noun agreement Arabic style, their straight, simple cold, synonyms successive iterations compliments and flattery and praise that the Timurid era had begun and there was also a testament to the Safavid period and it was a bit too seriously. Prose recent events in the major flaws, lack of reflection and circulation, and worst of all were the incidence of praise and flattery had defective Prose. (Bahar, Mohammad Taghi (1953) Stylistics Volume 3, Tehran, Sepehr / 255 )

Located in the Safavid era in what order and what level of writing prose comes down so hard that the person falls, however. Despite the imperfections and flaws in the prose of the period, looking at existing literature class of Akhbar and Condiments sweet as described, hyperbole, metaphor, etc., and it may not be worth literary prose.

"Sultans Akhbar top stories of celebrity and glamour Sahbqranan time, big name gelatine elegance God commands the nominal rulers of the names he crowned monogram on the floor. With the sentence of eternal force winds, financial affairs and property owners learn to extinction creator of the universe setting role the mystic realm of knowledge and knows the secrets unknown no Sanaei in praise and acknowledge the. Seat area means circle layout, switching seats Pira'i word associations, based on the description anxiety and helplessness. Instead what I'm talking about making a story, impostor short sighted, long tongue fabulous reader, ignorant of much conversation, monotheism and merit and is required to be put. (Pride, Timers, Abdel- Nabi (1641) leading akhbar, / manuscript, No. 358, parliament Library / Page 2)

\section{6. Taraz Al Akhbar prominent aspect of storytelling}

Taraz Al Akhbar is astonishing, as if everything about stories and storytelling has been described in detail and perfection, it is in fact a war that the author of many poems, according to her, it will help to storytelling composition and the various poems of great poets, from earliest to his contemporaries on various topics, and technical aspects of storytelling and storytelling are considered.

The preface of the book is the most important part of the chapter we find that the author of this story in Persian Iran and Turan and India are the narrators.

As previously mentioned, the first part of the book consists of short stories and poetry, often in the form of storytelling usually take them before the start of the Masnavi stories to the attention of the audience or the audience the so-called experts this a "pre reading " they say. Purpose of this book describes the rules and read the "story of Hamza". This is the important part of this story is dedicated to the introduction Abdel Nabi. As a leading Taraz Al Akhbar contains five chapters: the first chapter in the story of creation and the difference is invented traditions of philosophy, for example, refers to various beliefs about the creation of this story, of Arab a scientist from the story for the disposal of the Bani Abbas caliphs disease min for one set, and some believe that the story of the reign of the deficit and the rest of the story Khwaja Bouzarjomehr wise, and so different, and different beliefs about who invented this story the first chapter is the introduction. (Mohammad Jafar Mahjoub / articles / Iran letter / year 2 / spring 70).

In this chapter, these are:

"The Lord is not hidden knowledge and insight to those who seek Sahebqaran is a story, a legend is extremely sweet and extremely colorful Although the issue of truths that lie 
idle, reading and listening to the benefit of storytelling honor and respect that makes rich, thought to come from the void, the void in their pockets, and no intermediate tool to learn about the rulers and kings, emirs not born into the story." (Ibid / 19).

Then, according to the stories and storytelling of kings and ministers have considered the importance of Naby skilled storytelling and improvisation, memory and so he says:

"... The storytelling and memory should have a strong sense of the nature of the appeal; we must not indulge in Eccles stuff that brings oblivion, division, and time to talk about him. Not the way to neglect say, but the battle does not go to the party and read a story that does not transfer to another anecdote, and the nature of the gravitational force is the order of the to hear that everything is in learning improvisation, and to record so that it does not forget, even movements If the teacher is looking for imitator of his master could. "(Ibid / 20).

Third Preference of storytelling is with the poet because, as this is the "first because when one of the kings of the House of storytelling reads the story, makes sure that more or less at the Assemblies of ten tons of people and they will be accomplished, if the eloquent speakers of the clauses of this sort is difficult and eloquent exposition of the congregation, and when written, fun and sweet gestures work, and poems, good and of highquality all the talk about lines Reading a good read and the word was eager for it to end, from first to last, is a word far as the poet is the second reason [that] the poet says, ten times and it is correct shall, after making sure the listener 's heart was singing, storytelling improvisation says everything should be relevant and not wrong in his daily" (Trazalakhbar / 20).

The fourth chapter in the story of Don Juan story, humor, and thankfully they did not know and the homogeneity of the goodness before coming to this chapter, the author's storytelling in social behavior that should be speaking with regard to the religious prejudice the Safavid dynasty of India believes that some of the devices:

"God owns this gorgeous art technology that complies with the House vote should not be drinking stipulated in paragraph religious intolerance since the days of kings and rulers of each of the supreme value, religion, age and some of the other ritualistic unfrequented they Shi group and atheist community. The time to deliver God's way of bringing consumers and homogeneous generosity comes from the heart of sympathy may be obtained in this way, and because of his unhappy in the world to atone for his lies ... " (same / 20 and 21).

Abdel Nabi believes that storytelling is not the technology itself and is an unfinished story, the fifth-rate introduction of Taraz Al Akhbar has the storytelling proper etiquette when you read a story and sing the words of the so-called Saint-John is known as the "jewel of reading." As well as talking about and move, therefore, it has the most basic introduction.

Abdel Nabi said referring to the method of storytelling that has been split three ways: The Iranian, Turanian and Hindi in the context of what has been expressed as to how this approach is in the introduction chapter.

Imagination- exaggerated imagery and metaphors -in Taraz Al Akhbar:

The science of expression in Persian literature, what is regarded as the main goal, is getting to know different ways of saying the word with the most important tools used in the sense of imagery so the speaker or writer is considering the beauty of the word, the idea of using images as permitted in moderation, simile, metaphor, hyperbole, and especially in the realm of storytelling to a public audience in understanding the themes and concepts are not hard; doctor Shafie kadkani in his paper has seen as practice of this kind that: 
"What is the set of examples of metaphors and similes is reminded the influx of all these lifeless and inert descriptions, and it has no effect".

Despite their indulgence in some cases and also other defects impact on eloquent speaks. It seems to be some special to have class descriptions in prose, the major disadvantage is the lack of moderation in the literal meaning of the term.

Doctor Shafie kadkani believes there are two possibilities in the way of storytelling:

1. the authors of the books of these stories do not have to be something that people do not mention it, they have asked to be part of storytelling with fill phrases, as our journalists insist that they do not enjoy the poems published nor readers, however, it continues to fill pages and convince the reader.

2. Another possibility is that we get away from the historic center of this style of speech, and the beauty of the change in principles. We, today, cannot understand poems or enjoy, , but the people of that era and the era of storytelling that were not popular in the town, have understood and have been enjoying. (Look at the top akhbar / Shafi' Kadkani / year 3 / No.1 / 1060th spring / p. 116)

\section{CONCLUSION}

Cognitive load considered Taraz Al Akhbar as a treasure of great poets and writers of poetry and prose collection, which besides being a useful tool for understanding the narrative techniques of conversation, helps story -telling and narration, prose style and the strong and weak points and how the author describes the elements of nature and life is introduced. Contributing the culture and Persian literature is vast and huge resource for research in Persian literature and culture. Better understanding of the poetry and prose of the author and factors is expressed during this period, with the extent and variety of poems and prose texts, this effect is achieved

\section{References}

[1] Fakhr Alzamani, Abdel Nabi (1923). Haute Akhbar, / manuscript, No. 358, Library of Parliament.

[2] Anthology meanings (1920). Biography of the pub, Tehran, Iqbal.

[3] Spring, Mohammad Taghi (1953). Stylistics Volume 3, Tehran, Sepehr.

[4] Kadkani Shafie M. R. (1960). At the top Akhbar, essays, letters, Baharestan third year. 1; 109-122.

[5] Mahjub M. J. (1950). Essays, Iran Nameh, year IX, No. 2, pp. 168-211.

[6] Moin M. (1967). A volume of Persian culture, Tehran, ASHJA.

[7] Shamisa Cyrus (1968). Semantics (Second Edition), Tehran, Mitra

[8] Shamisa Cyrus (1966). Expression (Third Edition), Tehran, Mitra. 
[9] Najm Soheila (1969). Narration in Art, Art.

[10] Library, Museum and Document Center of Iran Parliament, website: www.ical.ir

[11] Ayoob Moradi, Mahmoud Kamali, Sara Chalak, Hooshang Izedi, International Letters of Social and Humanistic Sciences 13 (2014) 32-51.

( Received 16 March 2014; accepted 31 March 2014 ) 